\section{SPOROZOAN INFECTION}

To the Editor of ScIence: I have just detected, in an American recently arrived in the Philippine Islands from the United States, a case of infection with Isospora hominis Rivolta, 1878 (emend Dobell, 1919). Circumstances connected with the case lead me strongly to suspect that the infection was contracted in the United States. Inspection of the recent literature has disclosed that since 1918 , at least eleven cases of sporozoan infection (including Isospora) have been discovered in the United States. Four of these cases apparently are autochthonous. They will be found in the tables accompaning papers by Kofoid and his coworkers, ${ }^{1,2}$ on the examination of overseas and home service troops in New York. These findings have escaped comment for one reason or another and, as the patient studied by me has never been in any part of Europe-much less the Eastern Mediterranean area where coccidial infections seem to be endemic, I consider we have reason to suspect that dissemination of the parasite is occurring among the civilian population of the United States.

We have little knowledge of the elinical manifestations of "human coccidiosis" and no knowledge of its pathology. Reports indicate that the parasite is not especially harmful to adults, but too much should not be assumed in this direction. Especially should we be watchful for infections in children and in people of lowered vitality. The cysts of the coccidia are highly resistant to desiccation, and to the action of chemicals and disinfectants, and they remain viable for long periods of time-much longer than do the cysts of other intestinal protozoa infesting man, so that the parasite presents a difficult problem in epidemiology.

All available information should be gathered at this time, regarding the incidence of human coccidiosis in the United States, for it

1 Kofoid, Kornhauser and Plate, Jour. Amer. Med. Assoc., Vol. 72, p. 1721, 1919.

2 Kofoid and Swezy, N. O. Med. and Surg. Jour., Vol. 73, pp. 4-11, 1920. may be possible to trace the cases originating in the soldiers already observed, and other cases that it is not unlikely have originated from them by this time. Such studies can not begin too early. With the object of aiding such an investigation, I am, by authority of Professor Elmer D. Merrill, director of the Bureau of Science, sending preserved material from our case to the following specialists, where it will be available for comparison with any material that may be found in the United States:

Professors Gary N. Calkins, Columbia University, New York; Robert W. Hegner, Johns Hopkins University, Baltimore, Md.; Henry B. Ward, University of Illinois, Urbana, Ill.; Charles A. Kofoid, University of California, Berkeley, Calif.; R. B. Gibson, Iowa State University, Iowa City, Ia.; Ernest E. Tyzzer, Harvard University Medical School, Boston, Mass.; Kenneth M. Lynch, Medical College of the State of South Carolina, Charleston, S. C.; James C. Todd, University of Colorado, Boulder, Colo.; Mark F. Boyd, University of Texas, Galveston, Tex.; and Allen J. Smith, University of Pennsylvania.

Frank G. Haughwout

Bureau of ScIENCE, MANILA, P. I.

\section{SCIENTIFIC LITERATURE AND APPARATUS FOR ROUMANIA}

To the Editor of Science: You were so kind as to publish in ScIENce (April 8) my letter in which I showed: (1) That our Institutions do not possess American books and instruments; (2) that the disadvantageous exchange of our money since the war, prevents us from making scientific purchases in the United States; (3) that means should be found to remove a difficulty that hinders scientific relations.

This letter provoked the interest of the American universities and intellectuals. I received not only approvals but also gifts consisting of books and even scientific instruments.

We accept with gratitude all these manifestations of sympathy, but they do not 